\title{
CONSTITUTIVE EQUATIONS FOR ANNEALED AND EXPLOSIVELY SHOCKED IRON FOR APPLICATION TO HIGH STRAIN RATES AND LARGE STRAINS
}

\author{
B.D. GOLDTHORPE \\ DRA Military Division, Sevenoaks, Kent, Great-Britain
}

Résumé - Nous avons déterminé un modèle constitutif pour le fer recuit et choqué par explosif, applicable aux très grandes vitesses de déformation et très grandes déformations. Le modèle est fondé sur celui de Armstrong et Zirelli, mais avec modification de la dépendance en température. Les données expérimentales montrent un excellent accord avec ce modèle qui a de bonnes capacités de prédiction. L'effet d'un choc par explosif, bien qu'ayant un effet important sur les propriétés de matériau, ne demande qu'une simplemodification du modèle afin de lui donner le même degré d'accord et de prédiction que pour le matériau recuit.

\section{ABSTRACT}

A constitutive model has been determined for annealed and explosively shocked iron for application to very high strain rates and large strains. The model is based on that of Armstrong and Zerilli but with modified temperature dependence. The data shows an excellent fit to this model and has good predictive capabilities. The effect of explosive shock although having a very large effect on properties requires a simple modification to the model to give the same degree of fit and predictive capabilities as that for annealed material.

\section{INTRODUCTION}

In recent years there has been a considerable increase in interest in constitutive equations for a wide range of materials and particular emphasis has been placed on models with a sound physical basis as opposed to purely empirical representations. One of the important reasons for this increase in interest is the availability of large computers and highly developed computer codes which can model complex structural and deformation problems with remarkable accuracy. The use of these codes has shown that, particularly where large deformations are involved, the accuracy of the results is strongly dependent on the constitutive equation for the material that is used.

Constitutive equations based on fundamental characteristics of materials have been published by Klepaczco (1) and Fallansbee (2) for application to both FCC and BCC metals: Armstrong and Zerilli (3) have published separate models for BCC and FCC metals which are structurally very different. These models generally cover a wide range of strain rate and temperature but a very limited strain range (about 0.3 ) in the experimental determination of their coefficients. AND EXPLOSIVELY DRIVEN DEFORMATION

Many problems such as fracture, high velocity impact, adiabatic shear and explosively driven deformation can involve very large local strains and the constitutive equations for application to this type of problem should be valid and preferably determined over as wide a range of strain as possible. This raises a 
particularly difficult problem since high strain rate tests involve adiabatic heating which increases as the strain increases.

Consequently the analysis of test records in which the strain is significant requires a knowledge of two of the three generally unknown functions strain rate dependence, strain hardening and the temperature dependence of the material. This particular problem has been solved in previous work by working at low strains and thus avoiding large adiabatic heating effects. It is also significant that most work on high strain rate properties only provides valid data at or close to initial yield even though the tests themselves can involve quite large strains.

Explosively driven deformation can involve very large strains (true strains of two or more) in which the adiabatic heating can raise the temperature by $500-1000^{\circ} \mathrm{K}$. The problem of developing constitutive equations for this application is, therefore, particularly severe. There is, however, an additional problem associated with explosive loading and that is the effect of the shock itself on the properties. It has been known for many years that explosive shock causes substantial hardening of most, if not all, metallic materials but its effect on mechanical properties has not been studied in any detail. An analysis of explosively formed iron projectiles (EFP's) was carried out by Goldthorpe, Andrews and Hogwood (4) where the sequence of events was shown to be that in figure 1 . In this process the original iron with a hardness of 90 VPN is subjected to primary and secondary shocks which raise the temperature by about $180^{\circ} \mathrm{K}$ but without significant-macroscopic deformation. The hardness at this stage was shown to have increased to about $200 \mathrm{VPN}$ and the iron had a very densely twinned structure. The subsequent formation of the projectile was then shown to occur by deformation of the shocked material.

The whole of this explosive formation process cannot at present be represented by a single constitutive equation and on the basis of the observations in (4) it appears that post-shock deformation should be represented by a constitutive equation based on properties measured on material first subjected to an explosive shock wave at the appropriate shock pressure.

The material used in this investigation was a low carbon $(0.018 \mathrm{wt} \%)$ high purity iron which had been recrystallised at $600^{\circ} \mathrm{C}$ to a final grain size of about $30 \mu \mathrm{m}$. For the tests in the unshocked state iron in the above form was used. For the shocked iron material in the above form was machined into discs $50 \mathrm{~mm}$ diameter and $9 \mathrm{~mm}$ thick. These were then explosively shocked to $0.5 \mathrm{Mbar}$ in a plane wave generating assembly by the Centre d'Etudes de Gramat, France. This explosive shocking procedure produced negligible distortion of the discs but increased the hardness to about 200 VPN and gave the material a densely twinned structure.

In order to determine work hardening rates to large strains tension tests were carried out to the late stages of necking. At low strain rates the strain was determined by measuring the minimum diameter of the specimen as a function of load. True strains could therefore be readily calculated and the true stress was calculated using the standard Bridgemen (5) correction method for hydrastatic tension.

At strain rates up to $10 \mathrm{~s}^{-1}$ the curves were determined by stopping the test after small increments of strain. The temperature was then allowed to return to room temperature after the adiabatic heating and the specimen subsequently reloaded. taking the flow stress on re-loading this procedure enabled isothermal stress stress-strain curves at fairly high strain rates to be determined.

Strain rate dependence was determined primarily at low strains. The strain rates used varied from $10^{-3} \mathrm{~s}^{-1}$ to $10^{4} \mathrm{~s}^{-1}$ and involved the use of standard tensile tests and Hopkinson bar tests in both compression and tension. As implied in the previous section however some tension tests up to strain rates of $10 \mathrm{~s}^{-1}$ were 
carried out to large strains with the specific purpose measuring the strain rate sensitivity as a function of strain.

The measurement of the temperature dependence of the flow stress of iron, and other BCC metals, is complicated by the strain ageing phenomenon which causes a reversal of the normal thermal softening process due to increased mobility of nitrogen and carbon with increase in temperature. Clearly in a comprehensive constitutive model strain ageing effects should be included but it is doubtful whether they are of interest in the large strain models developed here. Thus although the method of manufacture of this iron left very small amounts of carbon in solution, and therefore relatively small strain ageing effects, the strain ageing temperature ranges were avoided.

At low strain rates this meant that the temperature range was kept below $400^{\circ} \mathrm{K}$ but valid tests could not be carried out above the strain ageing range $\left(800^{\circ} \mathrm{K}\right)$ because of thermal recovery, At high strain rates $\left(10^{3} \mathrm{~s}^{-1}\right)$ strain ageing does not start until about $600^{\circ} \mathrm{K}$ and so this allowed a greater test temperature range to be used.

4 RESULTS AND DETERMINATION OF THE CONSTITUTIVE EQUATIONS

\subsection{Work Hardening Results}

Isothermal work hardening curves were first measured at room temperature at strain rates of $10^{-3} \mathrm{~s}^{-1}$ and $10 \mathrm{~s}^{-1}$. These results are shown in figure 2 for both the annealed and shocked materials. It is evident that the effect of explosive shock

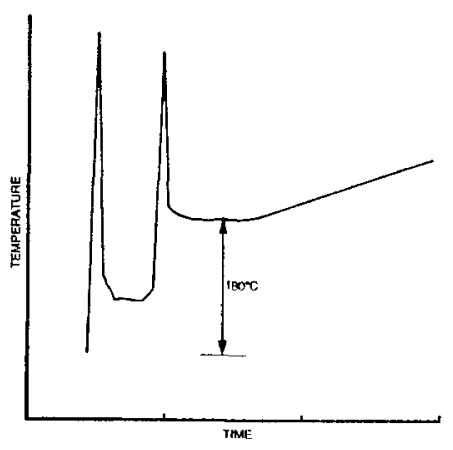

FIG. 1 PRIMARY AND REFLECTED SHOCK PEAKS

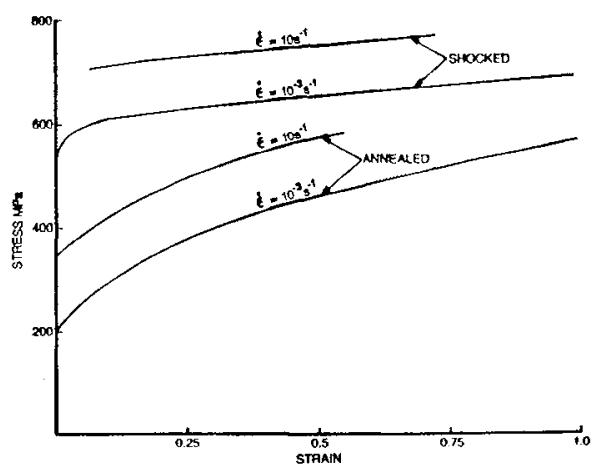

FIG. 2 STRESSISTRAIN CUAVES AT $21^{\circ} \mathrm{C}$

is to markedly reduce the work hardening rate and to raise the flow stress at a given strain and strain rate by about $350 \mathrm{MPa}$. An equally important feature is that for both shocked and unshocked materials the work hardening rate is independent of strain rate. This is a well established characteristic of BCC metals at small strains and is also a basic assumption of the constitutive equation proposed by Armstrong and Zerilli (3). The work hardening data indicated that this model may be valid up to strains of at least 1.0 and therefore provides a useful starting pont for these materials. This constitutive equation is usually expressed in the form:

$$
\sigma=C_{1}+C_{2} \exp \left(C_{3}+C_{4} \ln \dot{\epsilon}\right) \mathrm{T}+C_{5} \epsilon^{n}
$$

The constants $C_{5}$ and $n$ were determined from figure 2 and are given in Table 1 .

\subsection{Strain Rate Results}

In order to determine the strain rate dependence equation (1) can be expressed as:

$$
\ln \left(\sigma-C_{1}-C_{5} \epsilon^{n}\right)=\ln C_{2}+C_{4} T \ln \dot{\epsilon}+C_{3} T
$$


Compression and tensile test data measured at room temperature and over the strain rate range $10^{-3}$ to $10^{4} \mathrm{~s}^{-1}$ were used to test this relationship. The most reliable procedure was found to be to take values at a strain of 0.05 to avoid uncertainties over the initial yield value. The data for the unshocked material were plotted as $\ln \left(\sigma-C_{1}-C_{5} \epsilon^{n}\right)$ against $\ell \dot{e} \dot{\epsilon}$ wh the athermal constant $C_{1}$ determined as the value to give the best fit straight line. $C_{1}$ was found to have a value of $50 \mathrm{MPa}$ and it was assumed as a working hypothesis that the increase in flow stress due to shock would also act as an athermal constant $C_{6}$. For the shocked material $\ln \left(\sigma-C_{1}-C_{6}-C_{5} \epsilon^{n}\right)$, where $\mathrm{C}_{5}=350 \mathrm{MPa}$, was plotted against enc. All the data for shocked and unshocked material are shown in figure 3 where it can be seen that a good straight line is obtained and that if the above hypothesis is adopted then the strain rate sensitivities for the shocked and unshocked conditions are identical. Figure 3 gave a value of 0.000262 for the constant $C_{4}$ and it should also be noted that the intercept at $\ell \dot{n} \dot{\epsilon}=0$ is $\ell \mathrm{nC}_{2}+\mathrm{C}_{3} \mathrm{~T}$ and has a value of 5.52 .

\subsection{Thermal Softening and Threshold Stress}

One of the assumptions in equation (1) is that work hardening is independent of temperature and this has been shown to be at least approximately true at small strains (6). It is difficult to check the validity of this assumption at large strains because of the strain ageing effect. An initial critical check was carried out by measuring the work hardening curve at $200^{\circ} \mathrm{K}$ and a strain rate of $10 \mathrm{~s}^{-1}$ and comparing with results at $293^{\circ} \mathrm{K}$. It was found that there was a small but steady divergence with increases in strain. In common with a number of authors $(2,7)$ it was assumed that the temperature dependence of the shear modulus influences work hardening. A shear modulus correction using published data (10) applied to the $200^{\circ} \mathrm{K}$ and $293^{\circ} \mathrm{K}$ data brought the two sets of work hardening data into good agreement. It is not considered that this set of results is sufficient to prove a temperature dependence but at this stage it was adopted as a working hypothesis.

In order to test the temperature dependence predicted by equation (1) at low strains test data over a range of from $80^{\circ} \mathrm{K}$ to $300^{\circ} \mathrm{K}$ at a strain rate of $10^{-3} \mathrm{~s}^{-1}$ and a temperature range of $293^{\circ} \mathrm{K}$ to $593^{\circ} \mathrm{K}$ at a strain rate of $10^{3} \mathrm{~s}^{-1}$ were used for unshocked material. This was plotted in the form $\ln \left(\sigma-C_{1}-C_{5} \epsilon^{n}\right)$ against $T$ and is shown in figure 4. The data gives two straight lines which from equation (4) have

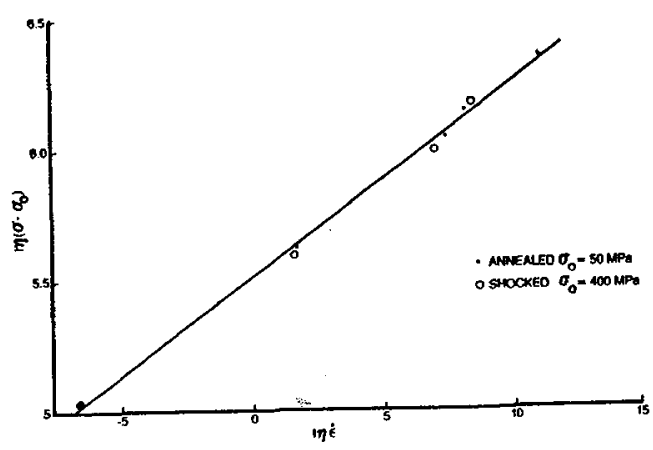

FIG. 3 STRAIN RATE SENSITIVITY

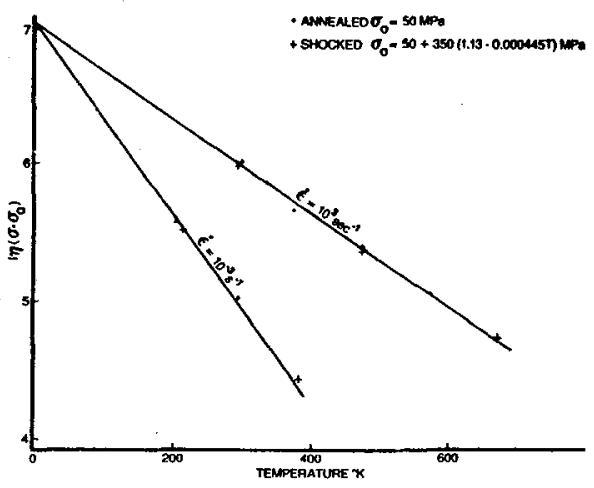

FIG. 4 DETERMINATION OF THE THERMAL COEFFICIENTS 
a slope of $\left(C_{3}+C_{4} \ln \dot{\epsilon}\right)$ and the intercept at $0^{\circ} \mathrm{K}$ is $\mathrm{C}_{2}$. When the data for shocked material were plotted in figure 4 in the form $\ln \left(\sigma-C_{1}-C_{5}-C_{5} \epsilon^{n}\right)$ it was found that as the temperature diverged from room temperature an increasingly large divergence from the unshocked data was obtained. However if the shear modulus correction was applied both the annealed and shocked materials fell on the same straight lines. This provided additional evidence that the terms outside the temperature dependent term in equation (1) are subject to a temperature dependence of the shear modulus. The values of the threshold stress $\mathrm{C}_{2}$ and the thermal softening coefficient can now be determined and they are $1150 \mathrm{MPa}$ and -0.00515 respectively. These values can be used to calculate the intercept on the strain rate curve (figure 3 ) and the calculated value is 5.521 and this compared to the measured value of 5.52 gives a good check on the internal consistency of the data.

The constitutive equations for annealed and explosively shocked iron can now be written:

$$
\sigma=C_{1}+C_{2} \exp \left(C_{3}+C_{4} \ln \dot{\epsilon}\right) T+\left(C_{5} \epsilon^{n}+C_{6}\right) \frac{\mu_{T}}{\mu_{293}}
$$

where $\mu_{\mathrm{T}}$ is the shear modulus at the prevailing temperature and $\mu_{293}$ the shear modulus at $293^{\circ} \mathrm{K}$. A linear expression for this from published data is:

$$
\frac{\mu_{\mathrm{T}}}{\mu^{293}}=1.13-0.000445 \mathrm{~T}
$$

The coefficients in equation (3) are given in Table I below.

\begin{tabular}{lccccccc} 
& \multicolumn{8}{c}{ Table I } \\
& $C_{1}$ & $C_{2}$ & $C_{3}$ & $C_{4}$ & $C_{5}$ & $n$ & $C_{6}$ \\
Annealed & 50 & 1130 & -0.00515 & 0.000262 & 357 & 0.52 & 0 \\
$\begin{array}{c}\text { Explosively } \\
\text { shocked }\end{array}$ & 50 & 1130 & -0.00515 & 0.000262 & 125 & 0.34 & 350
\end{tabular}

\section{PREDICTIVE CAPABILITY OF THE CONSTITUTIVE EQUATIONS}

An important requirement in the development of constitutive equations, particularly if they are to be used in computer modelling, is that they should be tested under as wide a range of known conditions as possible in order to establish the range of validity and their predictive capability. Two methods were available here, large strain Hopkinson bar tests which give a fully quantitative check and EFP formation which involves much larger strains and higher temperatures but which may be subject to greater uncertainties in the computational procedure.

\subsection{Hopkinson Bar Compression Tests}

These tests were performed at strain rates of $5 \times 10^{3} \mathrm{~s}^{-1}$ and $3 \times 10^{4} \mathrm{~s}^{-1}$ and true stress/strain records up to strains of about 1.0 were obtained.

The measured curves at a strain rate of $5 \times 10^{3} \mathrm{~s}^{-1}$ are shown in figure 5 for both shocked and unshocked material and for comparison curves calculated from equation (3) are also shown. Figure 6 shows similar results from tests at $3 \times 10^{4} \mathrm{~s}^{-1}$ and in both cases strains below 0.1 are omitted because of the uncertainties in the faster Hopkinson bar tests at these strains.

The shape of the curves and the absolute values of stress differs by only about $3 \%$ which is well within the accuracy that would be expected in a Hopkinson bar test. 


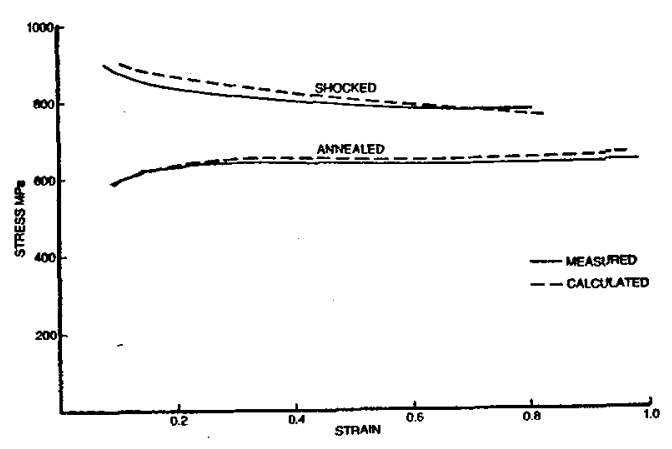

FIG. 5 HOPKINSON BAR TESTS AT $5 \times 10^{3} \mathrm{~s}^{\text {." }}$

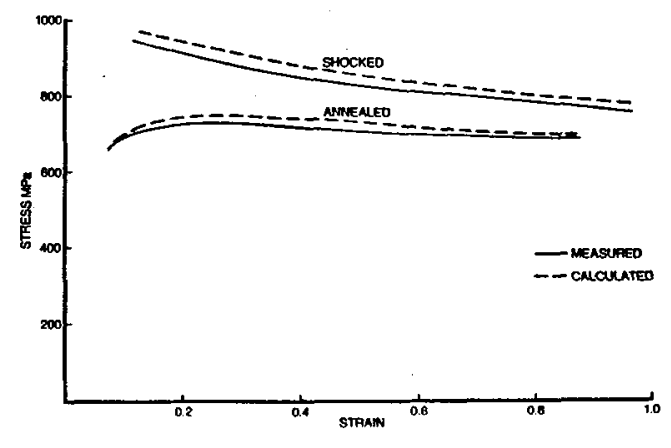

FIG. 6 HOPKINSON BAR TESTS AT $3 \times 10^{\circ} \mathrm{s}^{-1}$

The tests on shocked material show a different shape of curve because thermal softening is greater than work hardening throughout the test. The calculated curves again show very good agreement with the measured curves both in form and absolute values.

It would appear, therefore, that the constitutive equations for both shocked and unshocked iron are capable of accurately predicting the combined effects of strain, temperature and strain rate over a wide range of these variables.

\subsection{EFP Formation}

The range of temperature and strain involved in the formation of explosively formed projectiles is much greater than in a Hopkinson bar test and it is, therefore, a potentially much more demanding test of the constitutive equation.

Three fundamentally different EFP's have been modelled by my colleagues $\mathrm{P}$ Church and I Cullis (9) using the constitutive equation for the shocked material. Their detailed results are presented in a companion paper at this conference.

\section{DISCUSSION}

The basic form of the constitutive equations developed here is based on the original formulation of Armstrong and Zerilli (3) who in turn based their model for BCC metals on two characteristics that are well established at small strains. These are that strain hardening is independent of both strain rate and temperature. The present work has confirmed the former to strains of at least 1.0 but strain hardening does now appear to have a temperature dependence associated with that of the shear modulus. The effect of this is quite small for small strains and small temperature rises but can become a substantial factor at large strains and high temperatures.

The effects of explosive shock have been found to require relatively simple modification to model. The main effects are to raise the initial flow stress and reduce the work hardening rate. It has, therefore, the characteristics of a cold worked material and may be interpreted as an initial strain which in the iron used here would be about 1.0. However, the deformation mechanism in shock is quite different in that it takes place by very dense twinning and the actual strains involved in a shock pressure of $0.5 \mathrm{Mbar}$ are only about 0.2 . The effect of shock 
has, therefore, been treated here as an additional rate independent constant. It has also been found that explosive shock does not change the strain rate or temperature dependence, presumably because these are fundamental characteristics of the iron crystal lattice.

The predictive capabilities of the constitutive equations have been shown to be very good in both the fully quantitative Hopkinson bar tests and the less well characterised EFP formation (9). In this they represent a quite radical departure from empirical equations that are normally used in computer modelling since they now appear to have a predictive capability which offers the opportunity of quite realistic design studies.

Further more the development of the model for explosively shocked material has not only provided a means of carrying out computer modelling of explosively driven deformation but it has also demonstrated the principal effects of explosive shock in BCC metals. This should simplify the determination of constitutive equations for other shocked materials and thus enable the rapid advancement of computer modelling of these complex events.

\section{ACKNOWLEDGEMENTS}

The author would like to express his thanks to Dr J Harding of the University of Oxford, Dr J Field of the University of Cambridge and Dr D Parry of the University of Loughborough for provision of Hopkinson bar test facilities and to his colleagues $\mathrm{E}$ Jones, $\mathrm{M}$ Hogwood and A Gould for invaluable assistance in the acquisition of test data and many useful discussions.

\section{REFERENCES}

1 J R Klepaczco C Y Chien

2 P S Fallansbee

$3 \quad R$ W Armstrong F Zerilli

4 B D Goldthorpe M G Hogwood

$T$ Andrews

5 P W Bridgeman

6 D McLean

7 A H Cottrell

J R Stokes

8 Metals Handbook Vol 21979

9 I G Cullis

$P$ Church
J Mech and Phys of Solids. 34 p29 (1986).

International Conference on Impact Loading, Bremen FRG 1987.

Jnl de Physique 49 C3-529 1988.

28th Seminar on Novel Materials for Impact Loading Vol 1, Sept 1988.

Large Plastic Flow and Fracture, McGraw Hill.

Mechanical Properties of Metals, Wiley 1962.

Proc Roy Soc A $23317(1955$

Dymat 91 to be published 